http://dx.doi.org/10.4314/gil.v8i2.4

\title{
DISCOURSE INTONATION PATTERNS IN THE NON- INTERROGATIVE UTTERANCES OF SELECTED EDUCATED NIGERIAN SPEAKERS OF ENGLISH
}

\author{
Anthony Olabiyi Adejuwon
}

\begin{abstract}
Previous studies on English intonation have concentrated on its rulegoverned patterns; people's spontaneous utterance intonational choice characteristics are inadequately explored. This study investigated the interactionally-motivated intonation patterns of selected educated Nigerian speakers of English (ENSE) to determine the conformity of their spontaneous speech intonation patterns with their interactional context. David Brazil's Discourse Intonation (DI) model provided the theoretical framework. Thirty-two excerpts were purposively sampled from the spontaneous utterances of 17 purposively selected electronic media participants (Group A) and 15 focus group discussion participants (Group B). Structure and centrality to the messages of the excerpts informed the selection of the analysed non-interrogative tone units. Data were collected using textual analysis, FGD and questionnaire. Frequency and analysis of variance were used for quantitative analysis. The participants' non-interrogative tone-unit intonation patterns largely ran counter to DI, with 7 excerpts $(41.2 \%)$ from Group A and $5(33.3 \%)$ from Group B largely conforming to DI $(p=0.642)$, even when they did not necessarily obey formalised rules. Statistical p-value, being above 0.05 , showed no statistically significant difference in the mean between the two groups. The selected ENSE's intonational choices ran contrary to DI. ENSE's natural speech intonational choices are generally inconsistent as they follow no specific set of rules.
\end{abstract}

Keywords: Discourse intonation; Non-interrogative utterances; Educated Nigerian speakers of English; Natural speech; Formalised rules 


\section{Introduction}

English, a stress-timed language, is predominantly intonational because a syllable is stressed to render the word in which it occurs prominent within the tone unit, or to categorise the sentence in which the word containing the stressed syllable occurs in terms of sentence type. Stressing a syllable in a word may also be intended to indicate a particular meaning which the sentence in which the word occurs is meant to convey. On the other hand, Nigerian languages are tone languages; tone languages only employ a limited amount of superimposed intonation (Cruttenden, 1986: 10). This limited use of intonation in Nigerian languages makes its elaborate use in English a problem for Nigerian speakers of English as a Second Language (ESL).

Works on English intonation (Udofot, 1997 and 2007; Jowitt, 2000; Okon, 2001; Adesina, 2005; Akinjobi and Oladipupo, 2005 and 2010; Atoye, 2005 and Melefa, 2001) and the West African Examinations Council's (WAEC, 2013-2016: 210) provision for the teaching of English intonation have so far concentrated on its rulegoverned patterns. Most English Language Teaching (ELT) textbooks therefore present just a small set of intonation rules which allow a description of only a tiny part of intonation choices made in language as a whole (Cauldwell and Hewings, 1996: 333). The rules are, as such, inadequate to reflect the detailed intonation choices made in natural speech. Language, as a natural phenomenon and a means of communication, is dynamic and it changes in order to keep pace with the society. It can therefore not be restricted to a finite set of rules as people tend to express different shades of meanings and attitudes with varying intonation patterns understood by the interlocutors within the context of their interaction, but which are often not rule-based. This paper, therefore, investigates the interactionally-motivated intonation patterns of selected educated Nigerian speakers of English (ENSE) to determine the conformity of their spontaneous speech intonation patterns with the context of their interaction.

\section{Discourse Intonation (DI) Model}

Discourse Intonation (DI) model, which is a relatively new approach to the teaching and analysis of everyday speech, helps in enabling learners of English "to make their meanings and intentions clear to a listener" (Brazil, 1994: 2). This model, originated by David Brazil, is particularly useful in this age when there is increasing interest in research on the relationship between intonation choices and the speaker's communicative intention. More than a few researchers, according to Clark et al. (2007: 359), have, in recent years, "turned their attention to the role of intonation in discourse". This paper adopts the tone system of speaker choice variable in the DI model as its theoretical stance as a result of the currency of DI, its wide acceptance and intimate relevance to naturally-occurring speech. 
Tune, which Brazil (1997) calls tone, is described as pitch movements distinguished by their particular direction or contour (Coulthard, 1985: 101). Brazil (1997: 9-10) identifies five tunes, that is, fall, rise, fall-rise, rise-fall and level as the "complete set of possibilities". However, central to the choice of tune is the proclaiming/referring $(\mathrm{P} / \mathrm{R})$ opposition "that is realised by the two tunes most frequently found in many kinds of discourse, the 'fall' and the 'fall-rise"' (Brazil, 1997: 68). The fall portrays its tone unit as "something freshly introduced into the conversation" while the fall-rise depicts the tone unit it governs as "what we are talking about" (Brazil, 1997: 68-69). In other words, a falling tune is a proclaiming tune, whereas a rising tune is a referring tune. The graphic symbols $\searrow$ and $\nearrow$ are therefore replaced with the letters " $p$ " (proclaiming) and "r" (referring) respectively (Brazil 1997: 69).

\section{Methodology}

The participants for this study were made up of thirty-two educated Nigerian speakers of English (ENSE). The spontaneous utterances of seventeen of the participants (Group A) were recorded during discussion programmes and within-news interview sessions on the electronic media (Nigerian Television Authority - NTA, Africa Independent Television - AIT, Channels Television and Federal Radio Corporation of Nigeria - FRCN) while the interactionally-motivated utterances of the remaining fifteen participants (Group B) were recorded during focus group discussion (FGD) conducted by this researcher. The two sets of participants were selected to determine whether the domain of interaction could have an impact on the intonational choices of ENSE. The difference in the numbers of the participants in the two groups was due to the fact that the Group A participants were more constrained to use the noninterrogative tone units as they responded to the questions posed to them by their interviewers. A text containing seventeen excerpts (Excerpts A1 to A17) was prepared from the utterances of the Group A participants and another text of fifteen excerpts (B1 to B15 was prepared from the utterances of the participants in Group B (See Appendices $A$ and $B$ ). The underlined portions of the excerpts are the analysed tone units.

All the participants had educational qualifications ranging from National Certificate in Education (NCE) to university degrees, being senior government officials, university lecturers, medical doctors, etc. Educated Nigerian English which constitutes the most socially acceptable is claimed to be spoken mainly by university graduates (Gut, 2005: 154). However, Adejuwon (2011: 51) has discovered that obtaining a university degree in English Language does not necessarily make one better in the use of English intonation than those who learn this prosodic feature of speech 
elsewhere. What matters is the intensity or quality of the training coupled with the training facilities as well as the readiness or interest of the learner.

The data collected were analysed on the basis of the identification and the quantification of the intonation tunes used by the study sample. The precise intonation tunes used by the study participants were identified and the frequency of their occurrence was determined. The italicised symbols $\mathrm{p}$ (for proclaiming tune) and $\mathrm{r}$ (for referring tune) were adopted instead of the falling arrow $(\searrow)$ and the rising arrow $(\nearrow)$ respectively to indicate the tunes placed on the analysed tone units used for illustration in the data analysis section. This is in consonance with Brazil's (1997: 69) shift from the use of the arrows to the use of the symbols $p$ and $r$. The auditory approach was the main method used to identify the intonation patterns of the participants. It was found more reliable for the analysis of the data used for this study because the recordings were not devoid of extraneous sounds (or noise) which the instrumental approach could not sieve from the actual data. The researcher played back and listened to the recorded utterances of the study sample. The instrumental approach was applied only to the portions of the data that were recorded in relatively quiet environments and these were played back to the wasp (sfs/wasp) software on the computer for acoustic analysis. Some of the visual representations or spectrograms thus generated are used in the toneunit examples for the analysis. These tone units were extracted from the excerpts.

STATA version 11 (a statistical software package for data analysis created by Statacorp in 1985 but released for use in 2013), which allows command and minimizes error, was employed to do a univariate (descriptive/qualitative) analysis of the data. This brought out the frequencies and percentages of the occurrences of both the proclaiming (falling) and the referring (rising) tunes in the utterances of the participants. The conformity of the study sample with the DI model was thereby determined. The percentages of the participants' use of the proclaiming and the referring tunes (summary data) thus generated were subjected to ANOVA for inferential (quantitative) analysis. This brought out the level of statistical significance in the mean between the two groups.

\section{Data Analysis}

\subsection{Group A Participants' Intonational Choices in Non-interrogative Tone Units}

Going by the intonation patterns of the participants under study, it is clear that DI is still a strange model in the English intonation of educated Nigerian speakers of English (ENSE). We had complete conformity with DI in only 4 excerpts (Excerpts A2, A7, A9 and A13).

The proclaiming tune was employed in producing the lone non-interrogative tone unit in Excerpt A2. This non-sentence-final tone unit is obviously a prelude to a question which ordinarily should elicit information from an expert and this makes the 
choice of the proclaiming tune by the participant to conform to DI. Excerpt A7 contains 1 non-sentence-final and 1 sentence-final tone units which were both spoken with the proclaiming tune. The participant here was expressing a personal opinion; hence, the choice of the proclaiming tune for both tone units is in line with DI. The 4 analysed tone units in Excerpt A9 are divisible into 3 non-sentence-final and 1 sentence-final tone units. The proclaiming tune was placed on $25.0 \%$ of the tone units while $75.0 \%$ received the referring tune. The pattern here can be said to conform to DI as the tone units with the referring tune obviously establish common grounds between the speaker and his interviewer while the one bearing the proclaiming tune apparently provides information. At the same time, the excerpt complies with the grammatical intonation rules as the tone units taking the rising tune are non-sentence-final while the one with the falling tune is sentence-final. Excerpt A13 is composed of 1 non-sentence-final and 1 sentence-final tone units which were both produced with the referring tune. The 2 tone units state a fact that is known to both the speaker and his interviewee. The choice of the referring tune is therefore in line with DI.

For instance, the only tone unit in Excerpt A2 (Figure A1) was produced with a terminal falling pitch:

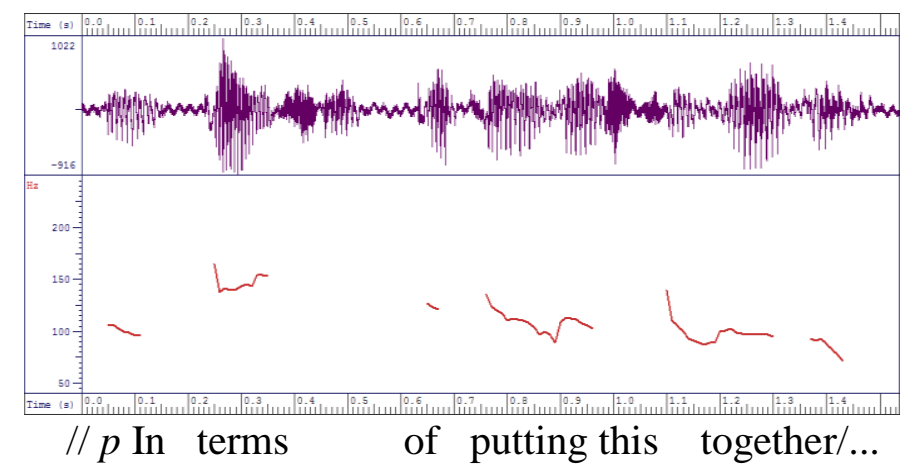

Figure A1: SFS screen capture of "In terms of putting this together ..."

The final tone unit in Excerpt A13 (Figure A2) was produced with a rising pitch at the end: 


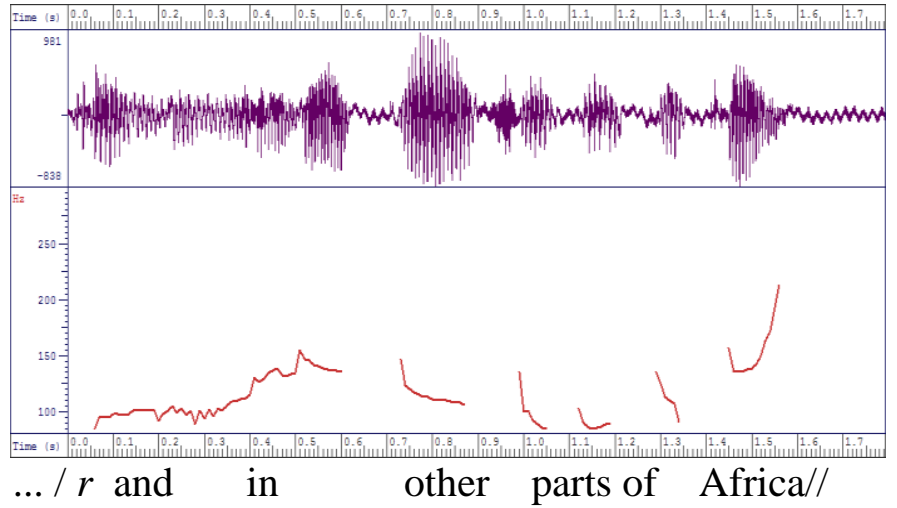

Figure A2: SFS screen capture of "... and in other parts of Africa"

Above average conformity with DI was recorded in 3 excerpts (Excerpts A5, A10 and A17). The participant who produced Excerpt A5 placed the proclaiming tune on all the 6 tone units constituting the excerpt ( 3 non-sentence-final and 3 sentencefinal). The choice of the proclaiming tune by the participant here is largely in consonance with DI as he was apparently giving information to his interviewer. It is only the third tone unit (Figure A3) that can be said to constitute shared knowledge because it states what people (obviously including the interviewer) used to know in the past and as such should take a referring tune, like its introductory phrase, instead of the proclaiming tune placed on it:

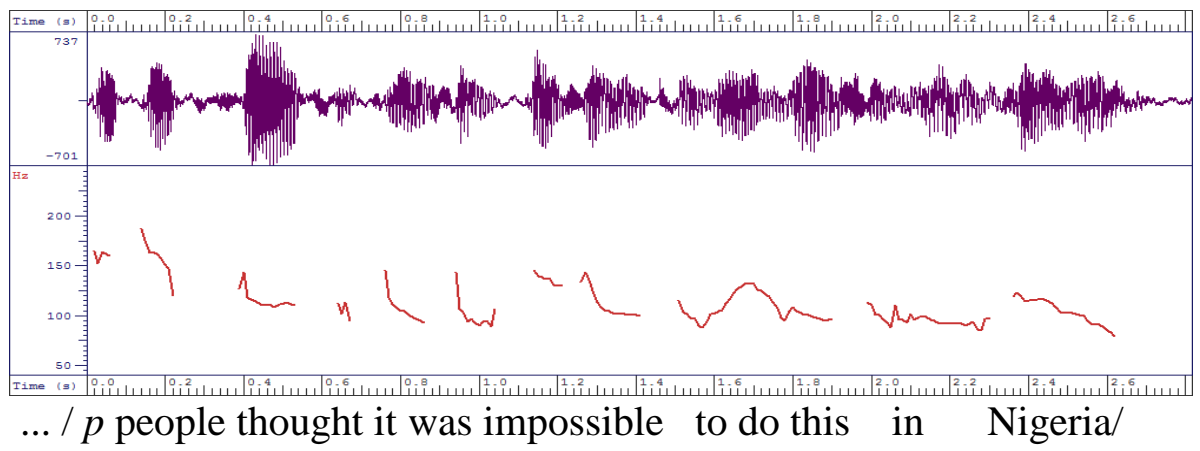

Figure A3: SFS screen capture of "... people thought it was impossible to do this in Nigeria"

The 6 non-interrogative tone units in Excerpt A10 include 4 non-sentence-final and 2 sentence-final tone units. The participant, who was apparently giving information with no presumption of common grounds between him and his interviewer, rightfully used the proclaiming tune to produce 5 tone units, but placed the referring tune on the remaining 1. As a government functionary, he was privy to the fact that the President 
Adejuwon: Discourse Intonation Patterns in the Non-Interrogative Utterances of Selected Educated Nigerian Speakers of English

had given certain directives. His choice of the rising tune on 1 of the tone units (Figure A4), a non-sentence-final tone unit, is therefore grammatical rather than discoursal:

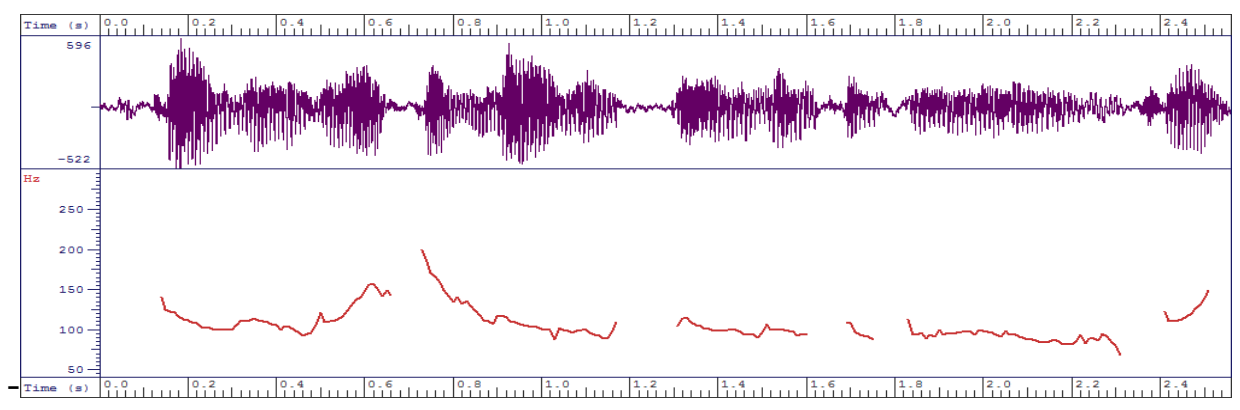

// $r$ It has been directed by the President and Commander-in-Chief/...

Figure A4: SFS screen capture of "It has been directed by the President and Commander-in-Chief"

The speaker of Excerpt A17, who was obviously expressing his opinion on a national issue, uttered $60.0 \%$ of the 5 tone units ( 1 non-sentence-final and 4 sentencefinal) with the proclaiming tune while the remaining $40.0 \%$ were said using the referring tune. The first 2 tone units and the last 1, which were produced with the proclaiming tune, are in accord with DI. Placing the referring tune on 2 of the tone units, which were also intended to pass information, renders the intonation tune choice for the affected tone units contra-DI. One of the 2 tone units (Figure A5) with the terminal rising pitch is:

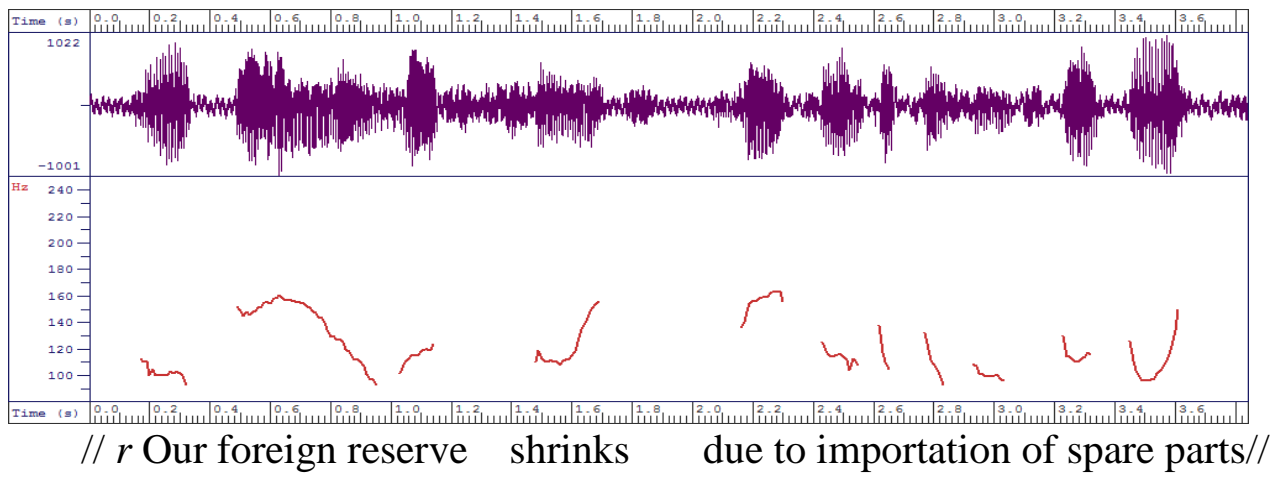

Figure A5: SFS screen capture of "Our foreign reserve shrinks due to importation of spare parts"

An average agreement with DI was recorded in 1 excerpt (Excerpt A12) while a below average compliance with DI was the case in 1 excerpt (Excerpt A14). The choice of the proclaiming tune in the last 2 (1 non-sentence-final, 1 sentence-final) of the 4 analysed tone units in Excerpt A12 is obviously in accord with DI because these 
tone units are actually conveying information. There is, however, a mix-up of tunes in the remaining 2 tone units (Figures A6 and A7) as the one that is referring to a shared knowledge (Figure A6 - a sentence-final tone unit) was spoken with a proclaiming tune while the one that is introducing new information (Figure A7 - a non-sentence-final tone unit) was produced with the referring tune:

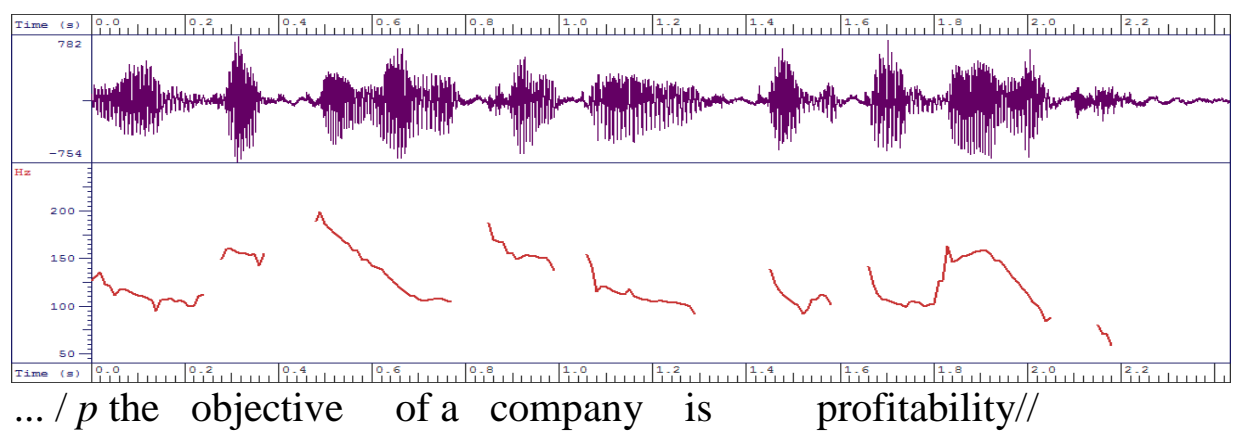

Figure A6: SFS screen capture of "... the objective of a company is profitability"

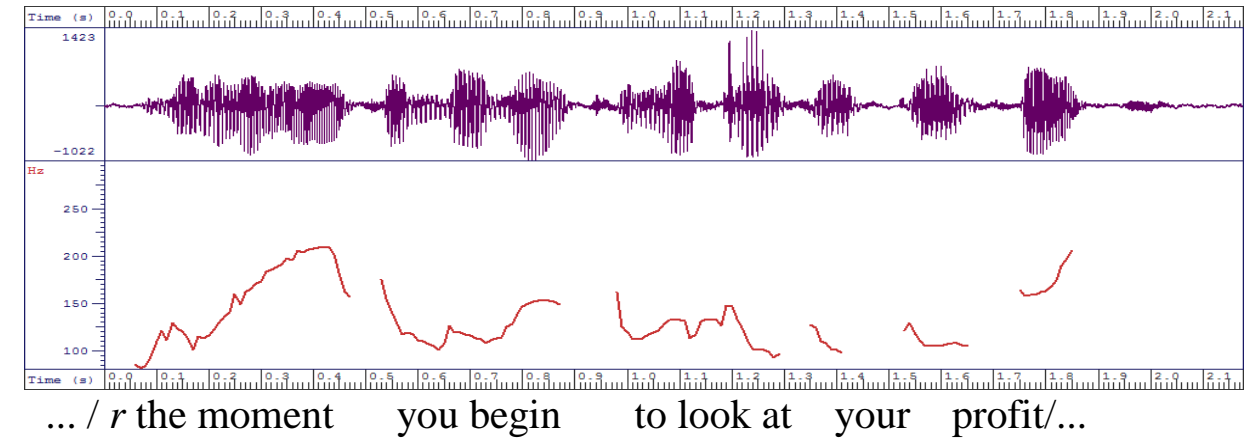

Figure A7: SFS screen capture of "... the moment you begin to look at your profit"

Meanwhile, 8 out of the 17 excerpts (47.1\%) were not in accord with DI (Excerpts A1, A3, A4, A6, A8, A11, A15 and A16). Only 1 of the 8 tone units in Excerpt A1 (the only one with the referring tune) conformed to DI. The speaker of Excerpt A3, who was introduced by her interviewer as a graduate of English, simply used the grammatical intonation rules set in ELT textbooks (known as Systemic Intonation or SI) to place the referring tune on the 3 non-sentence-final tone units and the proclaiming tune on the only sentence-final tone unit in the excerpt. She was however supposed to give expert information to someone who was supposedly finding out about her business with the use of the proclaiming tune all through.

As is the case in Excerpt 1, we have an indiscriminate deployment of the proclaiming and the referring tunes in Excerpt A4. The use of the referring tune on the first tone unit is apparently in agreement with DI, but this cannot be said about the 
proclaiming tune choice in the second tone unit. If the content of the first tone unit is a known fact, that of the second, which is the purpose of the first, should not be a secret. The third tone unit ought to take a proclaiming tune to comply with DI instead of the referring tune used by the participant because she was actually emphatically expressing her mind. The fourth, fifth, sixth and seventh tone units are apparently stating the obvious, especially with the overt use of the expressions: "as usual" and "everyone knew". They therefore ought to have been uttered with the referring tune to conform to DI instead of the proclaiming tune placed on them. The haphazard use of the two intonation tunes is further brought out in the last three tone units analysed in this excerpt. All of them are expressing common knowledge and therefore should take the referring tune to be in agreement with DI. Only the ninth tone unit bears the referring tune while the eighth (non-sentence-final) and the tenth (sentence-final) tone units were uttered with the proclaiming tune. Like Excerpt A1, the intonational choices in this excerpt are neither in agreement with DI nor rule-based intonation patterns.

Excerpt A6 is obviously referring to a common ground. From the question that follows and the answer given by the interviewee, it is apparent that the speaker here knew that his co-interlocutor was aware of the fact conveyed in the only tone unit in that excerpt. To conform to DI therefore, the tone unit should have been said with the referring tune rather than the proclaiming tune employed. The speaker of Excerpt A8 was apparently giving her personal opinion, which means she was giving information, but she used the referring tune on 2 of the 4 tone units. These 2 tone units are nonsentence-final. Moreover, 1 of the 2 tone units on which she used the proclaiming tune is a sentence-final tone unit. This means that she mostly adhered to SI, instead of DI, while she inadvertently used the proclaiming tune on a non-sentence-final tone unit. From the context of interaction in Group A's text, the contribution of the speaker of Excerpt A11 constitutes shared knowledge between him and his co-interactant. The use of the proclaiming tune on the 5 tone units in the excerpt is therefore not in consonance with DI.

The participant in Excerpt A15 also mixed up the tunes in his production of the 6 tone units constituting the excerpt. The first 2 tone units are clearly stating a common ground between the speaker of the utterance and his interviewer, based on a report they saw together. The choice of the proclaiming tune for them is therefore alien to DI. The 4 tone units said with the referring tune are actually offering suggestions (information); the choice of the referring tune by the speaker is therefore out of place in DI. Only $30.0 \%$ of the 10 tone units in Excerpt A16 conform to DI in terms of intonation tune choice while $70.0 \%$ do not. From the context of this excerpt, the speaker here saw the first 2 tone units as conveying a common fact which all Nigerians knew about, especially with his overt statement that "and I know Nigerians are proud of us". His choice of the proclaiming tune is therefore not in agreement with DI. The participant's 
choice of the referring tune on the first of the next 2 tone units is contrary to DI, while the use of the proclaiming tune on the second one is in conformity with DI. Also, the remaining 6 tone units were employed to give specific information on the plight of the speaker's constituents (i.e. people of his constituency) as their Representative. The use of the referring tune on the first 4 of these tone units is therefore inappropriate in DI while the choice of the proclaiming tune in uttering the last 2 is in conformity with DI. The haphazard use of intonation tunes by the participants is exemplified in Figures A8 and A9 from Excerpt A15:

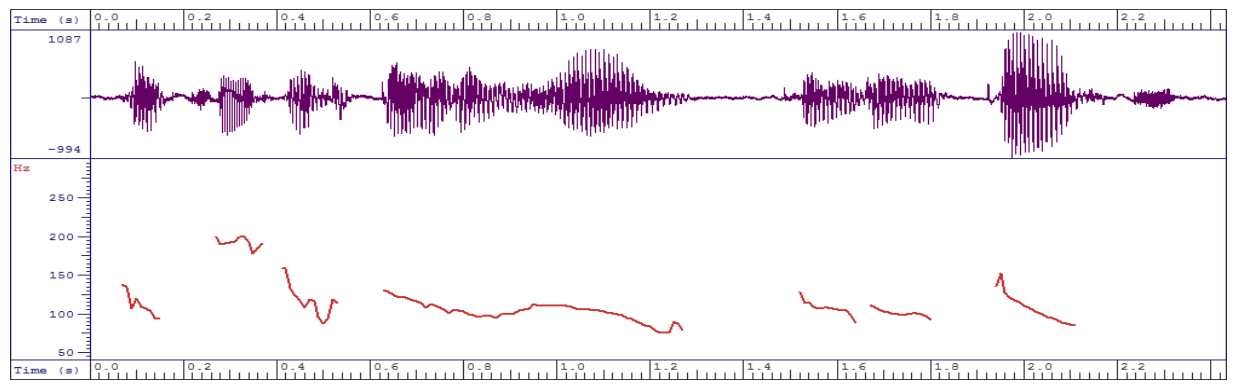

$/ / p$ I think we depend on oil/ $p$ from the report/...

Figure A8: SFS screen capture of "I think we depend on oil, from the report"

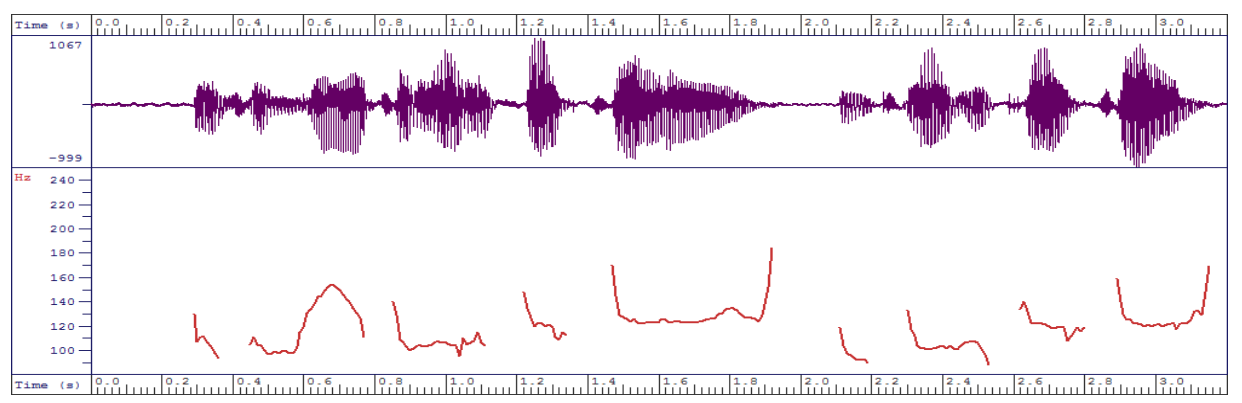

I $r$ we should go into manufacturing/ $r$ into agriculture/...

Figure A9: SFS screen capture of "... we should go into manufacturing, into agriculture"

If we add the excerpts that are in total accord with DI and those with above average conformity with DI, we only have 7 out of 17 excerpts $(41.2 \%)$ that largely subscribe to DI. It means then that a vast majority of educated Nigerians are not aware of, and do not use, DI in the aspect of non-interrogative tone units. This is attributable to the novelty of the DI approach and the fact that it is not yet promoted in the English Language syllabuses in the Nigerian educational system, especially at the pre-tertiary 
levels. Even at the tertiary level, only the English language major students are minimally exposed to DI through mentioning it as just the discourse function of intonation without any detailed discussion of its principles in the classroom.

\subsection{Group B Participants' Intonational Choices in Non-interrogative Tone Units}

It is clear that DI is thus far a strange model in the English intonation of educated Nigerian speakers of English (ENSE). Complete conformity with DI was recorded in just 2 (Excerpts B9 and B14) of the 15 excerpts from the utterances of the Group B participants. The choice of the proclaiming tune by the participant to produce all the 3 (1 non-sentence-final and 2 sentence-final) analysed tone units in Excerpt B9 subscribes to the DI model as the participant obviously saw his contribution as an informative response to the request for information in the preceding excerpt. This is made glaring in the participant's conclusion of the excerpt as his own view. The participant in Excerpt B14 (Figure B1) uttered his 2 non-interrogative tone units with the proclaiming tune, though 1 is sentence-final and the other is non-sentence-final. He was explaining his earlier question in order to disambiguate it, thereby giving information. His choice of the proclaiming tune is therefore in consonance with DI:

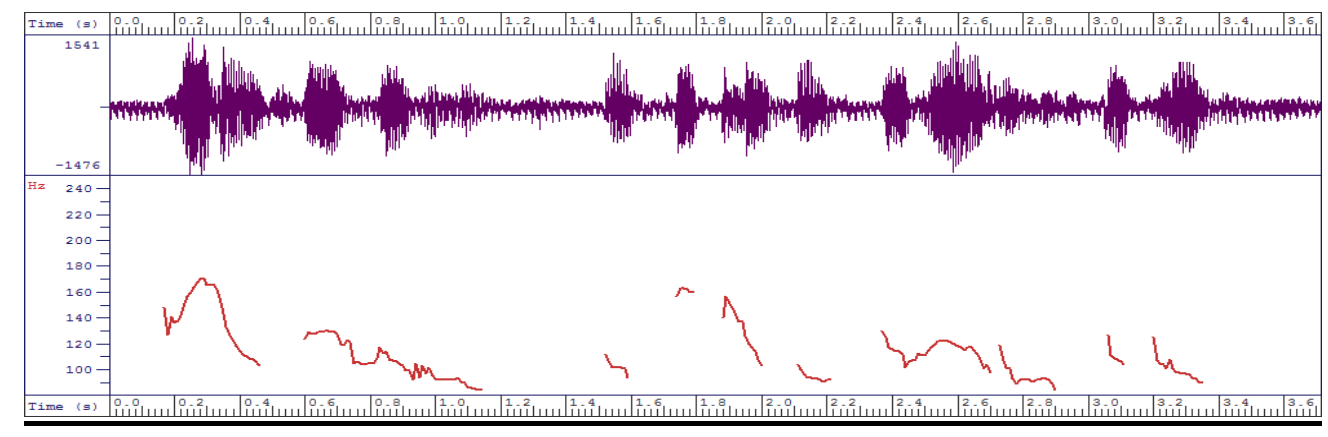

$/ / p$ When I say government/ $p$ I'm talking about federal and the state levels//

Figure B1: SFS screen capture of "When I say government, I'm talking about federal and the state levels"

Above average conformity with DI was recorded in 3 excerpts (Excerpts B5, B12 and B13) while below average compliance with DI was the case in 4 excerpts (Excerpts B2, B3, B7 and B10). The production of 6 out of the 7 tone units in Excerpt B5 (representing $85.7 \%$ ) with the proclaiming tune, irrespective of the sentence-final (3) or non-sentence-final (4) status of the tone units, makes the excerpt to be mostly in tune with DI. Having been asked for his opinion on how Boko Haram could be eradicated, the contribution of the participant here could be considered as information- 
giving. This view is reinforced by the participant's use of expressions such as "I don't think..." and "I think...".

The choice of tunes in Excerpt B12, which comprises 7 tone units, mainly agrees with the DI model as the 5 tone units with the proclaiming tune are actually seen to be giving information. This was also lexically indicated by the participant with his introductory tone unit "To me...". The Northern Nigerian participant here saw the FGD as an opportunity to inform the public that Boko Haram was not an Islamic sect, contrary to the belief of many Nigerians. The participant in Excerpt B13 (Figure B2) was obviously drawing from some common ground between him and his interviewer who was a fellow Northern Nigerian. He therefore spoke almost all his tone units, including 3 sentence-final tone units, with the referring tune in a manner of "I'm just confirming what you know":

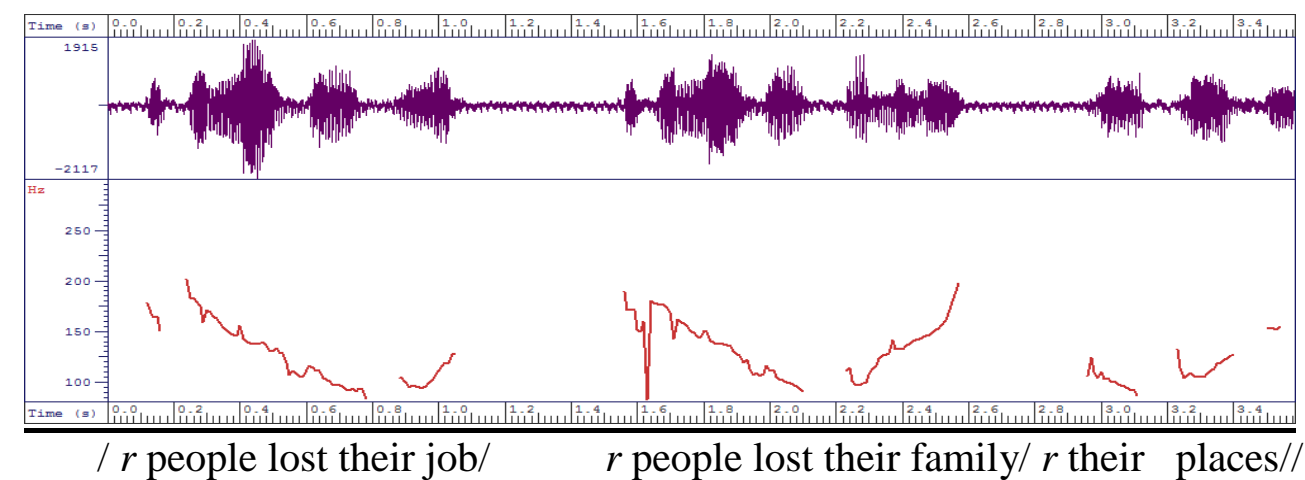

Figure B2: SFS screen capture of "... people lost their jobs; people lost their family, their places"

The participant who produced Excerpt B2 (one of the below-average conformity excerpts) chose the proclaiming tune to say 6 analysed tone units (out of 9) which were meant to confirm some common grounds. The excerpt is, as a result, largely contrary to DI as $66.7 \%$ of the tone units in the excerpt run counter to DI with respect to the tune placed on them. The first of the 6 tone units (Figure B3), for instance, merely echoes what has been stated by a previous discussant in Excerpt B1. Yet, it was ended with a falling pitch: 
Adejuwon: Discourse Intonation Patterns in the Non-Interrogative Utterances of Selected Educated Nigerian Speakers of English

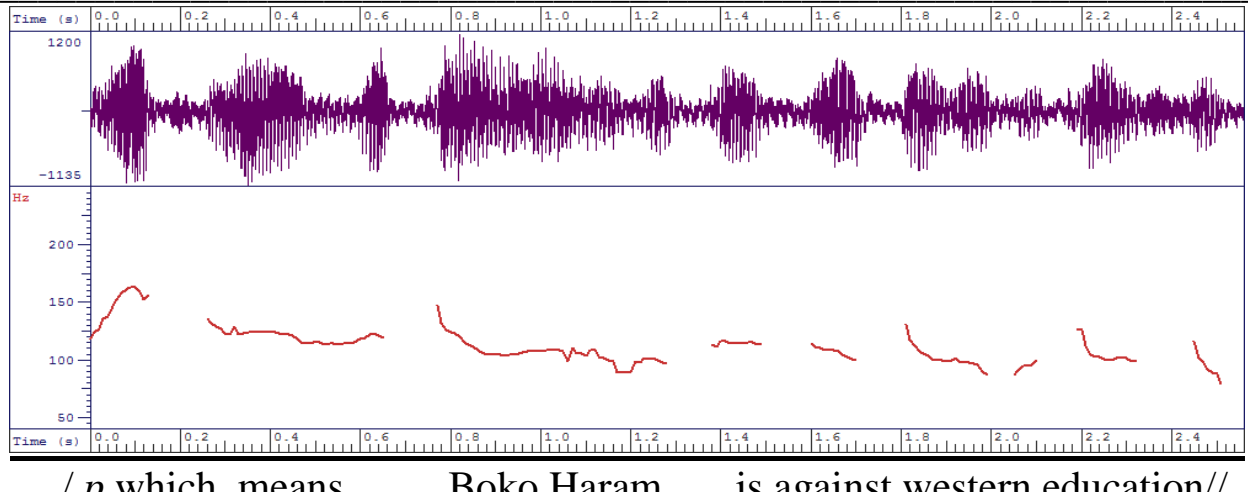

.../ $p$ which means Boko Haram is against western education//

Figure B3: SFS screen capture of "... which means Boko Haram is against western education"

Six out of the 15 excerpts $(40.0 \%)$ are completely not in accord with DI (Excerpts B1, B4, B6, B8, B11 and B15). For instance, the analysed tone unit in Excerpt B8 (Figure B4) had the proclaiming tune placed on it by the participant. Being a tone unit which merely summarises the contents of Excerpt B7, the participant's use of the proclaiming tune to produce it renders this tone unit not conforming to DI. A preceding tone unit to the analysed non-interrogative tone unit ("Okay") which bears the referring tune lends credence to this claim:

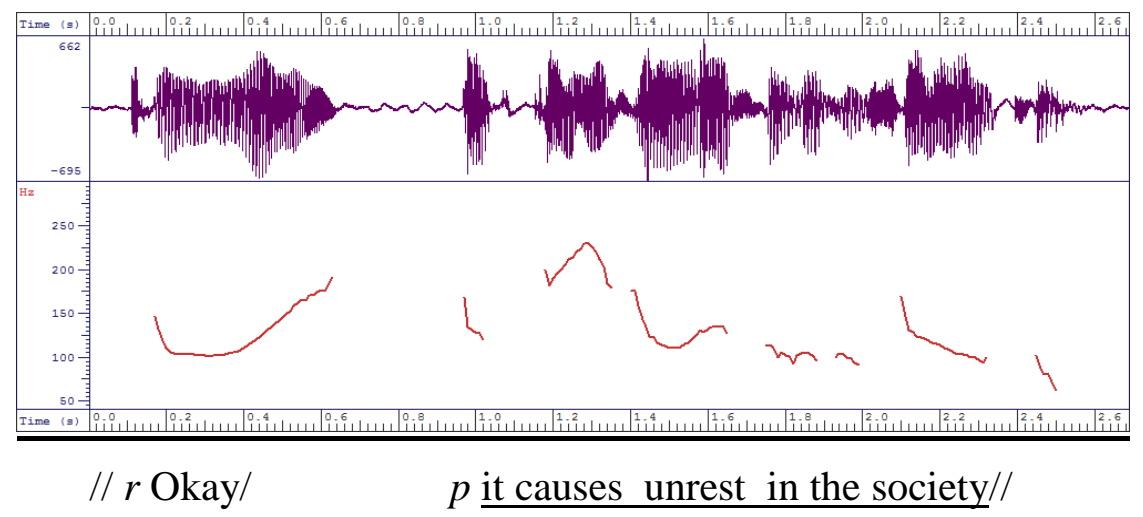

Figure B4: SFS screen capture of "Okay, it causes unrest in the society"

An addition of the excerpts that are in total accord with DI and those with above average conformity with DI would give us only 5 out of 15 excerpts $(33.3 \%)$ that largely subscribe to DI. Relating this to the findings in the analysis of Group A's noninterrogative tone-unit intonation patterns, it is emphatically clear that a vast majority of ENSE are not aware of, and do not use, DI in the aspect of non-interrogative tone units with only 12 of a total of $32(37.5 \%)$ non-interrogative tone-unit excerpts for both 
groups conforming to DI. In addition to the reasons earlier adduced for ENSE's non awareness and non use of DI, it is also a fact that in most elementary schools in Nigeria, only one tutor teaches all subjects without taking cognisance of specialisation. Also, many secondary schools lack competent teachers of English; they therefore make do with graduates of cognate disciplines in the humanities.

\subsection{Analysis of Variance of the Overall Study Population's Non-interrogative Tone-unit Intonational Choices}

It would be recalled that the Group A participants largely conformed to DI in the intonational choices of 7 out of their 17 (41.2\%) non-interrogative tone-unit excerpts whereas the participants in Group B recorded considerable conformity with DI in the intonation patterns of 5 out of their 15 (33.3\%) non-interrogative tone unit excerpts. The table below shows the analysis of variance (ANOVA) indicating the level of statistical significance in the mean between the two groups.

\subsubsection{Analysis of variance of Groups A and B}

\begin{tabular}{|l|l|l|l|l|l|}
\hline \multicolumn{7}{|c|}{ Analysis of variance } \\
\hline Sources & $\begin{array}{l}\text { Sum of } \\
\text { square }\end{array}$ & $\begin{array}{l}\text { Degree of } \\
\text { freedom }\end{array}$ & $\begin{array}{l}\text { Mean of } \\
\text { square }\end{array}$ & F-cal & P-Value \\
\hline Between & 0.051 & 1 & 0.051 & 0.221 & 0.642 \\
\hline Within & 6.934 & 30 & 0.231 & & \\
\cline { 1 - 4 } Total & 6.985 & 31 & \multicolumn{2}{|l}{} \\
\cline { 1 - 3 } $\mathrm{P}=0.05$ & & &
\end{tabular}

It is observable from the ANOVA table above that the significance level is 0.642 $(p=.642)$, which is above 0.05 . Therefore, there is no statistically significant difference in the mean between Groups A and B. Most of the remaining 10 Group A excerpts, 8 out of 10 (Excerpts A1, A3, A4, A6, A8, A11, A15 and A16), were not in accord with DI while average agreement with DI was recorded in 1 excerpt (Excerpt A12) and below average compliance with DI was the case in 1 excerpt (Excerpt A14). Only 4 of the 10 Group B excerpts (Excerpts B2, B3, B7 and B10) considered not-conforming with DI recorded below average conformity while a larger number, 6 excerpts (Excerpts B1, B4, B6, B8, B11 and B15), were completely not in agreement with DI. This indicates that domain of interaction, whether on the electronic media or in ordinary 
face-to-face interaction, does not effect any significant difference among educated Nigerian speakers of English in terms of their non-conformity with DI in noninterrogative tone-unit patterns. ENSE are therefore basically the same in their nonconformity with DI in non-interrogative tone-unit intonational choices.

\section{Conclusion}

It has been found out, through the data analysis, that there is no marked difference between the two groups' (i.e. Groups A and B) intonation patterns as both groups were found to be mainly the same in their non-conformity with DI as regards their intonational choices in non-interrogative tone units. The study revealed a remarkable gap between the natural speech intonation patterns of the selected ENSE and their interactional context. The intonation patterns of both groups of participants in the noninterrogative tone units largely ran counter to the Discourse Intonation (DI) model, even when they did not necessarily obey formalised rules. Therefore, educated Nigerian speakers of English (ENSE) generally lack consistency in their natural speech intonational choices with regard to non-interrogative tone units. It is recommended that the discourse intonation principles be included in the English Language syllabuses and that English intonation be taught to elementary school pupils and learners at other levels by experts in English phonology to enhance its proficient use.

\section{References}

Adejuwon, A. (2011). The English Intonation Patterns of Radio Broadcasters in Western Nigeria. Saarbrücken: LAP LAMBERT Academic Publishing GmbH \& Co. KG.

Adesina, O.B. (2005). Intonation in the Speech of Senior Secondary School Students in Ibadan North Local Government Area of Oyo State. M.A. Project. Department of English. University of Ibadan.

Akinjobi, A. and Oladipupo, O. (2005). Patterns of Intonation of Some Nigerian Television Reporters. Ibadan Journal of European Studies 5: 1-16. and (2010). Intonation and Attitude in Nigerian English. A Journal of Contemporary Research 7.1: 159-167.

Atoye, R.O. (2005). Non-native Perception and Interpretation of English Intonation. Nordic Journal of African Studies 14.1: 26-42. 
Brazil, D. (1994). Pronunciation for Advanced Learners of English: Teacher's Book. Cambridge: Cambridge University Press. . (1997). The Communicative Value of Intonation in English. Cambridge: Cambridge University Press.

Cauldwell, R. and Hewings, M. (1996). Intonation rules in ELT textbooks. ELT Journal 50.4: 327-334. London: Oxford University Press.

Clark, J., Yallop, C. and Fletcher, J. (2007). An Introduction to Phonetics and Phonology. 3rd ed. Oxford: Blackwell Publishing Ltd.

Coulthard, M. (1985). Intonation: An Introduction to Discourse Analysis. London: Longman.

Cruttenden, A. (1986). Intonation. Cambridge: Cambridge University Press.

Gut, U. (2005). Nigerian English Prosody. English World-wide 26.2: 153-177.

Jowitt, D. (2000). Patterns of Nigerian English intonation. English world-wide 21.1: 63-80.

Melefa, O.M. (2011). Rhythmic and Intonational Patterns of NN24's Newscasting. M.A. Project, Department of English, University of Ibadan.

Okon, B.A. (2001). The Intonational Structure of Nigerian English. Ph.D. Thesis. Department of English, University of Ibadan. The West African Examinations Council (no date). New Regulations and Syllabuses for West African Senior School Certificate Examination, 2013-2016.

The West African Examinations Council (no date). New Regulations and Syllabuses for West African Senior School Certificate Examination, 2013-2016.

Udofot, I. (1997). The Rhythm of Spoken Nigerian English. PhD. Thesis, University of Uyo. . (2007). A Tonal Analysis of Standard Nigerian English. Journal of Nigerian English Studies Association 3.1: 58-68. 


\section{APPENDIX A}

\section{Group A Participants' Intonation Patterns}

A1. // $\searrow$ Nigeria is very much a transitional society// $\searrow \mathrm{We}$ are moving towards modernity/ $\searrow$ we are not yet there// $\searrow \mathrm{We}$ are a very traditional society// $\nearrow \mathrm{We}$ are trying/ $\nearrow$ what I think Jonathan got his finger on it by saying/ $\searrow$ his was a transformational leadership// $\searrow$ I've not seen enough transformation/ $\searrow \underline{\text { but it's }}$ an aspiration $/ \searrow \underline{\text { a transit/ }} \nearrow$ from what used to be/ $\searrow$ to where we are today// $\searrow$ The Nigerian universities are in various stages of lack of preparedness $/ ~ \checkmark$ but there are some high quality institutions like the one I'm associated with now//

A2. // $\$ In terms of putting this together/ $\nearrow$ what are the materials/ $\nearrow$ what are the tools you need in actually putting this together//

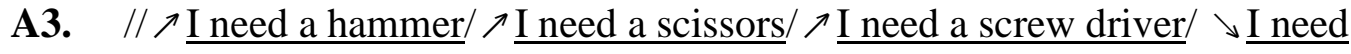
chemical glue// $\searrow$ This is what does the wrapping//

A4. $/ / \nearrow$ NEMA and the Federal Government have met $/ \nearrow$ time and time/ $\searrow$ and time

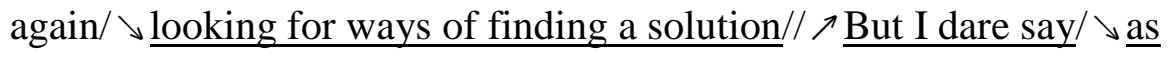
$\underline{\text { usual }} / \searrow$ not much has been done so far $/ ~ \$ because everyone knew that there was going to be flooding/ $\searrow$ especially in the northern part of the country// $\checkmark$ We seem to know what to do/ $\nearrow$ but how to enforce/ $\nearrow$ or implement/ $\searrow$ whatever we decide to do/ $\searrow$ is always the problem// $\nearrow$ It's not enough to continue to sit down/ $\searrow$ people are losing property/ $\nearrow$ children are being washed away/ $\searrow$ houses are washed away// $\searrow$ And it's unfortunate/ $\searrow$ that it is at this point in time/ $\searrow$ we are still meeting/ $\searrow$ and talking/ $\searrow$ when the disaster is already here/ $\searrow$ and another one is looming//

A5. // $\$ I guess it's ever increasing/ $\searrow$ and majorly/ $\underline{\text { it's because of awareness } / / ~} \nearrow \mathrm{A}$ few years ago/ $\searrow$ people thought it was impossible to do this in Nigeria/ $\checkmark$ but now the belief is there/ $\searrow$ that we do it here// $\supset$ Therefore/ $\searrow$ the patronage also is ever increasing//

A6. // $\searrow$ Dynamo Kiev have somehow threatened the other teams in Europe// $\searrow$ Do you think people expect anything good from Dynamo Kiev this time around// 
A7. // $\searrow$ think the only positive thing we can expect from Dynamo Kiev/ $\neg$ perhaps $/ \searrow$ is for them to rack up as many points as possible//

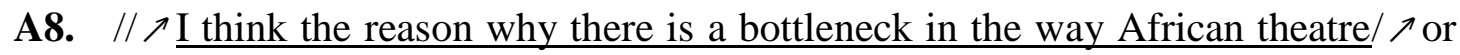
Nigerian theatre/ $\searrow$ isn't advancing to that Broadway level/ $\nearrow$ is because we don't have a model that works/ $\searrow$ and we haven't figured out how to create value//

A9. $/ / \searrow$ Yes $/ \searrow$ but all the groups $/ \nearrow$ the producers $/ \nearrow$ the theatre practitioners $/ \nearrow$ the venue builders/ $\searrow$ must take off at the same time//

A10. // $\backslash$ The collaboration here is to highlight the role that even the military can play this time/ $\triangle$ given the national emergency// $\nearrow$ It has been directed by the President and Commander-in-Chief/ $\searrow$ that all efforts must be made/ $\nearrow$ to be able to cover this area in a specific time period/ $\searrow$ and the best crop of logistics for this type of operation/ $\searrow$ when it comes to the nitty-gritty/ $\searrow$ is the military//

A11. // $\searrow$ The issues remain community-based/ $\searrow$ to a large extent $/ / \searrow$ Federal government does not go to allocate land in states// $\backslash$ It is the state governments that do that $/ /$ The state governments do not go to communities to generate the $\underline{\operatorname{trash}} / / \searrow$ It is these communities that have the duty/ $\searrow$ to ensure that they take charge of their environment//

A12. // $\searrow$ Yes// $\searrow$ Ultimately/ $\searrow$ the objective of a company is profitability// $\nearrow$ But you see/ $\nearrow$ in business/ $\nearrow$ the moment you begin to look at your profit/ $\searrow \underline{\text { without }}$ looking at the good of your stakeholders/ $\searrow$ there would be discord//

A13. $/ / \nearrow$ You are trying to create food security in Nigeria/ $\nearrow$ and in other parts of Africa// $\searrow$ But these are roles/ $\searrow$ that some people think/ $\nearrow$ can best be secured/ $\searrow$ by the government of the day//

A14. $/ / \nearrow$ First of all/ $\searrow$ in the part of Nigeria I come from/ $\nearrow$ they say/ $\searrow$ a hungry man is an angry man $/ / \nearrow$ The moment you are able to ensure that your people are $\underline{\text { fed } / ~} \backslash$ fifty to seventy percent of the problems are solved $/ / . . . / / \backslash D$ Don't forget/ $\searrow$ the moment your next door neighbour is unable to feed/ $\searrow$ you have a security issue// $\searrow$ Coming to the involvement of the government/ $\searrow$ I haven't seen a much more concerned government/ $\checkmark$ in trying to get food security for our people/ $\searrow$ than this current government// 
Adejuwon: Discourse Intonation Patterns in the Non-Interrogative Utterances of Selected Educated Nigerian Speakers of English

A15. // $\searrow$ I think we depend on oil $/ \searrow$ from the report/ $\$ we depend on oil basically//

$\nearrow \mathrm{So} / \nearrow$ we should go into manufacturing/ $\nearrow$ into agriculture/ $\nearrow$ into other areas/ $\nearrow$ so we would be able to make sure that we also earn income from them $/ /$

A16. // $\backslash$ At House of Representatives $/ ~ \$ we have done our part $/ / \neg$ We have done it well/ $\searrow$ and I know Nigerians are proud of us// $\nearrow$ For you to know that we have done our own part/ $\searrow$ we go to the constituencies through the committees// $\nearrow$ My people are not having food $/ \nearrow$ roads are not good $/ \nearrow$ hospital not working/ $\nearrow$ educational system in shamble/ $\backslash$ power is not okay/ $\searrow$ and we keep on having crimes here and there//

A17. // $\searrow \underline{\text { Mr President should stop the importation of any spare part } / / ~} \backslash$ Save our foreign exchange// $\nearrow$ Our foreign reserve shrinks due to importation of spare parts $/ / \nearrow$ This will create job for our people/ $\ \underline{\text { and also will create }}$ capacities all over the country//

\section{APPENDIX B}

\section{Group B Participants' Intonation Patterns}

B1. // Boko Haram simply means/ $\searrow$ if you want to put it literally/ $\searrow \underline{\text { we can say it's }}$ anti-book $/ / \triangle$ But the main idea of Boko Haram is anti-western education//

B2. // $\searrow$ What I'll like to say/ $\nearrow$ though the meaning of Boko Haram is book is forbidden/ $\searrow$ or book is bad/ $\searrow$ which means Boko Haram is against western education $/ / \searrow$ But looking at those that have been attacked by these people/ $\ \underline{\text { this }}$ sect called Boko Haram/ $\nearrow$ can we really say only the educated have been attacked// $\nearrow$ They go to parks/ $\nearrow$ they bomb people/ $\searrow$ they go to different locations $/ / \triangle$ Though they go to schools as well/ $\backslash$ but we cannot say only the educated have been attacked//

B3. // $\mathrm{It}$ 's a recent development $/ / \neg$ But if you check the history of Boko

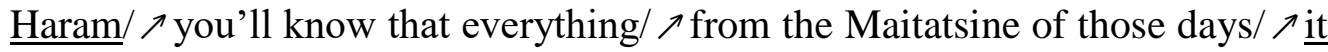
has always evolved/ $\nearrow$ because they have leaders// $\nearrow$ The government will capture one/ $\nearrow$ and they keep succeeding/ $\searrow$ and it's now what it is $/ / \searrow$ The name Boko Haram may be recent/ $\$ but the history has been a long thing coming// 
B4. // To me/ $\searrow$ I'll say this is just the beginning/ $\searrow$ if care is not taken// $\searrow$ There are innocent lives that have really gone for this $/ \nearrow$ just like the students that were kidnapped/ $\searrow$ then the recent bombing that happened in Abuja// $>$ We can see that so many people lost their lives/ $\nearrow$ and the issue of the vehicles that were burnt $/ \nearrow$ people that were selling/ $\searrow$ so many things $/ / \nearrow$ Even economically/ $\searrow$ we are down// $\nearrow$ The more they are destroying/ $\searrow$ the more the economy of Nigeria is going down//

B5. //ノTo stop Boko Haram in the country/ $\nearrow$ government should engage in

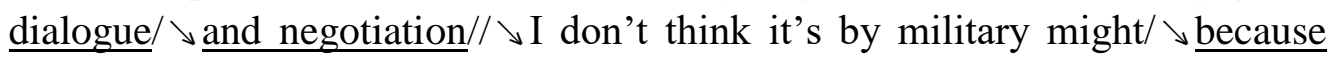

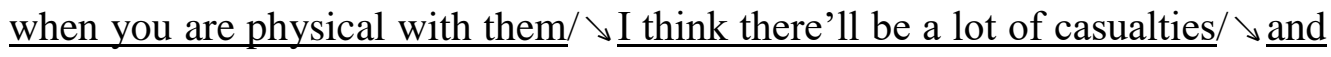
mayhem in the country//... $\searrow$ the solution lies in the hands of the government// $\searrow$ They should wake up// $\searrow$ They know what to do/ $\searrow$ I don't need to tell the government what to do//

B6. $/ / \searrow \underline{\text { Insurgency is a rebellious act against the government } / / ~} \supset \underline{\mathrm{It} \text { is a rebellious act }}$ against the government//

B7. // $\searrow$ Who are insurgents// $\searrow$ Like I once mentioned before/ $\nearrow$ we have militants from Niger Delta/ $\nearrow$ we have OPC from western part of Nigeria/ $\searrow$ we have Boko from northern side of Nigeria/ $\searrow$ and the Ibos who are the Biafrans// $\nearrow$ It's like I said/ $\searrow$ anybody who has decided to rebel against a constituted authority is an insurgent//

B8. $/ / \neg \mathrm{Okay} / \searrow$ it causes unrest in the society// $\searrow$ Is it a recent development//

B9. // $\searrow$ Yes/ $\$ because we are known to be the happiest people on $\underline{\text { earth }} / / \searrow$ Insurgency in Nigeria is just developing recently/ $\searrow$ and what is causing it is probably some linkage with some Islamic ideology// $\checkmark$ That's my own point of view//

B10. // $\searrow$ Sure// $\searrow$ To me $/ \searrow$ number one effect is reduction in population in the northern part of the country// $\searrow \underline{\text { In economics/ }} \searrow$ under investment/ $\searrow \underline{I \text { was made }}$ to understand that population has a role to play in a community's $\underline{\text { GDP// }} \searrow$ Number two/ $\searrow$ the economy of the country is fluctuating// $\searrow$ God has

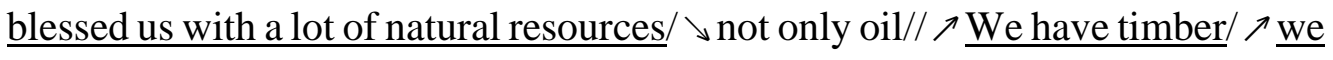

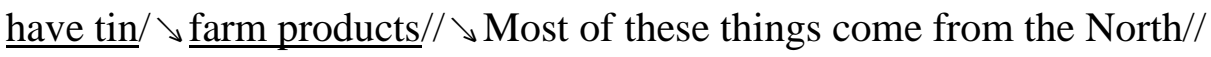


Adejuwon: Discourse Intonation Patterns in the Non-Interrogative Utterances of Selected Educated Nigerian Speakers of English

B11. // To the best of my understanding/ $\nearrow$ insurgency is any rebellion against the authority/ $\searrow$ or against the state/ $\searrow$ that is/ $\searrow$ against the government $/ / \nearrow$ Any act of aggression against the people/ $\supset$ against the authority/ $\searrow$ it is an insurgency//

B12. // 7 To me/ $\searrow$ insurgents are not Muslims $/ \searrow$ they are not Christians $/ / \searrow$ These are the people who have no fear of God// $\searrow$ These are the people who are enemies of this country// $\searrow$ These are the people who are enemies of the northern part of the country// $\nearrow$ These are the people who are sponsored by some people who are outside the North $/ \nearrow$ who are outside the country/ $\searrow$ who are all-out to destroy the progress of the northern part of the country//

B13. $/ / \nearrow$ Yes/ $\nearrow$ it has a lot of effect/ $\nearrow$ economically/ $\nearrow$ social life/ $/$ in every aspect of life/ $/ \searrow$ It has affected people's life// $\nearrow$ It caused death/ $\nearrow$ people lost their job/ $\nearrow$ people lost their family/ $\nearrow$ their places// $\nearrow$ They lost everything// $\searrow$ They became refugees in their own country// $\gg \mathrm{So} / \searrow$ it's a great tragedy in the country//

B14. A: // $\searrow$ Is the government sincere in their fighting against insurgency// $\searrow \underline{\text { When I }}$ say government/ $\searrow$ I'm talking about federal and the state levels//

B15. B: // $\nearrow$ The federal government/ $\nearrow$ actually/ $\nearrow$ based on how I look at everything/

$\searrow$ they are not putting enough resources// $\nearrow$ Even if they are doing that/

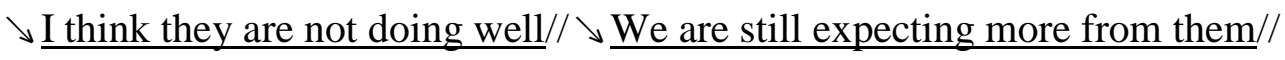

$\searrow$ We need more than hundred percent from them// 